\title{
Zanzibar-omanere og Oman-zanzibarere
}

\section{BINDESTREKER OVER DET INDISKE HAV - OG VIDERE}

Swahili-talende osmanere med bakgrunn fra Zanzibar er en lite kjent minoritet i dagens Oman. Swahili-omanerne er en påminnelse om landets historiske forbindelser over Det indiske hav.

Av Anne K. Bang, ansatt ved Senter for Midtøsten og islamske studier ved Universitetet i Bergen. Også forfatter av fire bøker.

Swahilitalende omanere med øst-afrikansk bakgrunn har en helt spesiell historie og posisjon i dagens Oman. Motsatt gjør zanzibarere med omansk bakgrunn seg igjen gjeldende på Zanzibar. Begge gruppers historie skriver seg fra Omans periode som kolonimakt i Øst-Afrika, og deres eksistens er slik sett en påminnelse om lange og dype historiske forbindelser mellom mennesker på ulike sider av Det indiske hav. Likevel er de nærmest ikke-eksisterende i offentlige statistikker og oversikter både i Zanzibar (en delvis autonom del av Tanzania) og i Oman - to relativt unge nasjonalstater som på ulike måter har fremelsket nasjonal enhet hos sine transnasjonale befolkninger. Denne artikkelen er et forsøk på å identifisere en bindestreksbefolkning på to sider av et stort hav.

\section{Takallamu Ki-Omani?}

Det er ikke vanskelig å finne swahilitalende omanere i det moderne Muscat, hovedstaden i Oman. En nokså sikker metode er å gå inn i en bank og lytte til samtalen mellom de middelaldrende, kvinnelige ansatte.
Med stor sannsynlighet foregår samtalen på swahili og ikke på landets offisielle språk, arabisk. Hvis du tiltaler dem på swahili, vil de svare på swahili. Snakker du til dem på engelsk, vil de svare på engelsk. Hvis du derimot tiltaler dem på arabisk, vil de se forvirret på deg og gå over til engelsk ved første anledning. Så utbredt er swahili i Muscat at det til og med har blitt utgitt en egen ordbok over det som på folkemunne kalles "ki-omani", det vil si swahili slik det snakkes i Oman.

Nå er det selvsagt slik at svært mange samtaler i det moderne Muscat foregår på andre språk enn arabisk, ettersom byen består av arbeidskraft fra store deler av verden. Hindi, urdu, gujarati, engelsk, tagalog, singalesisk og tamil høres overalt og er gjenlyd av arbeidsinnvandringen som har funnet sted siden oljeproduksjonen kom i gang for alvor på I970-tallet. I tillegg høres altså swahili, og oftere på såkalte hvitsnipparbeidsplasser enn på byggesteder og blant veiarbeidere. De swahilitalende i Oman er nemlig ikke fremmedarbeidere - de er statsborgere, omanere, med alt det innbær- 


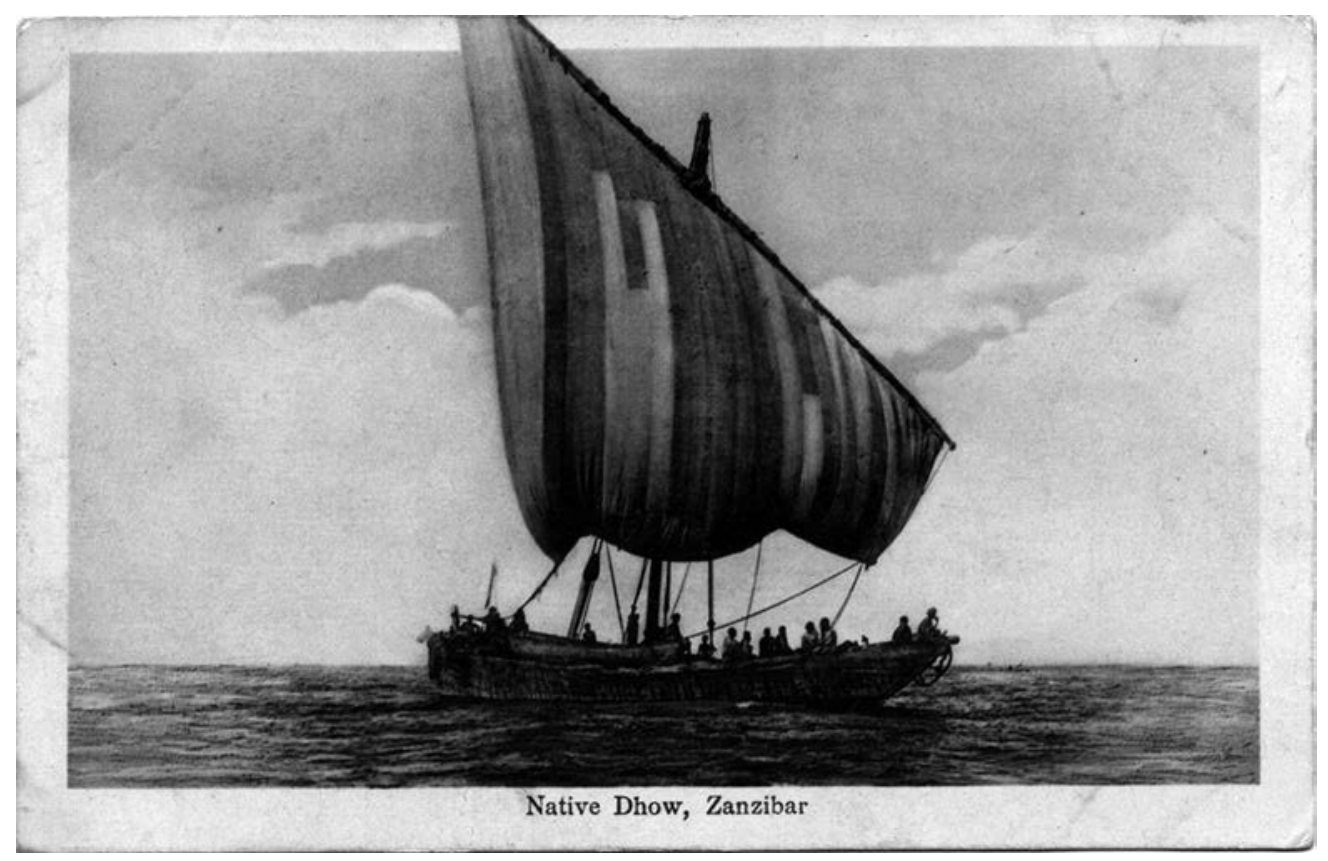

Gammelt postkort med en arabisk dhow som seiler på Det indiske hav utenfor Zanzibar.

er av privilegier i en arabisk oljenasjon. De går under ulike benevnelser, mange av dem med den typiske bindestreken som betegner mennesker med mer enn ett etnisk eller geografisk opphav: Zanziomanere, swahili-omanere eller afroomanere. Og, som mange andre bindestreksbefolkninger lar de seg vanskelig fange opp av nasjonalstatens tall og tale.

En kveld i 2002 befant jeg meg på et møte i Oman Historical Association. Møtet ble holdt inne på området til landets statskontrollerte oljeselskap Petroleum Development Oman. Den store gassflammen i raffineriet Minat al-Fahl lyste opp den nattmørke veien til lokalet. Innenfor befant det seg rundt 50 personer, og tema for kvelden var Omans historie på Zanzibar. Lederen for foreningen var en omaner fra en familie som hadde holdt seg hjemme under hele Omans kolonitid. Publikum, derimot, var denne kvelden nesten uten unntak swahilitalende omanere. Foreleseren var en britisk arkitekt som hadde fotografert storslagne bygninger i Zanzibar By og samlet inn historier om de ulike husene. Det skulle vise seg at disse husene hadde mer historie enn foreleseren kanskje kunne ønske.

Allerede ved første lysbilde rakte en mann i salen opp hånden: "Det var min bestefars hus," ropte han til foreleseren som ble stående forloren foran bildet av et hus i bydelen Baghani i Zanizbar. "Jeg vokste opp der, i den gaten," fortsatte mannen og pekte på bildet. Neste bilde fikk samme kommentar fra salen, og neste bilde også, til foreleserens åpenbare frustrasjon. Til slutt måtte historieforeningens leder gripe inn og minne forsamlingen på at "dette tross alt dreide seg om Omans historie" og at forsamlingen "som omanere" burde vente til etter foredraget med å kommentere. Gradvis falt salen til ro. En mann 


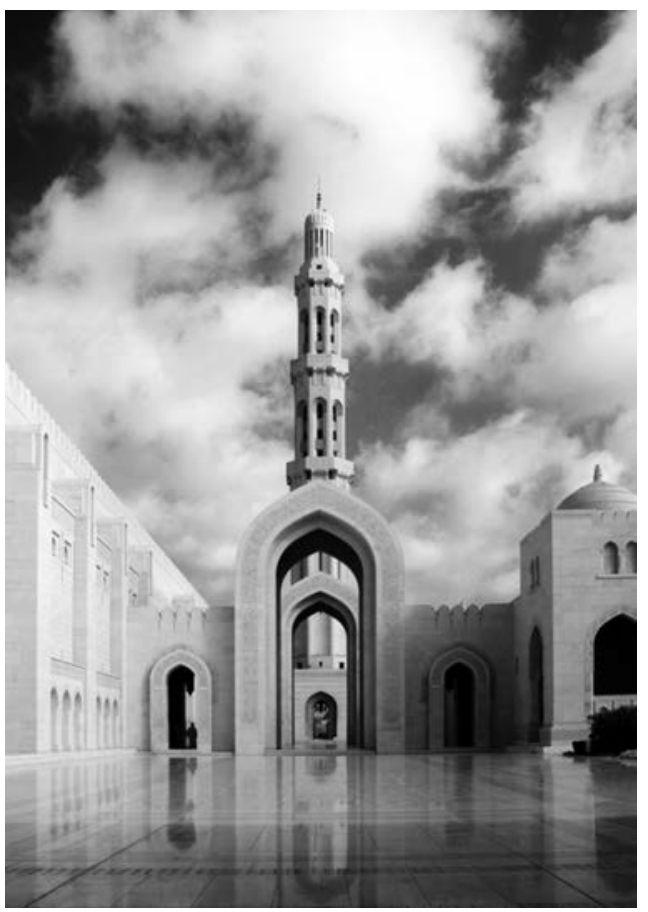

Sultanens Stormoské i Muscat. Alle muslimer er velkomne.

ved siden av meg så på meg og hvisket: "Dette er ikke Omans historie, you see? Dette er vår historie."

\section{Swahili-omaneren i statistikken}

Om de er lette å finne i bybildet, er det langt vanskeligere å finne de swahilitalende omanerne i landets offisielle statistikker. Folketellinger og oversikt over befolkningen fordelt etter gruppe er i Oman heftet med stor usikkerhet. For eksempel er det umulig å oppdrive oversikter over hvilke morsmål som tales blant landets innbyggere; arabisk blir overalt presentert som det eneste offisielle språket.

Sultanatet Oman som moderne nasjonalstat er en relativt ny "oppfinnelse”, født av statskuppet i I970 der den nåværende sultan Qaboos b. Said avsatte sin fremmedfiendtlige far. Etter maktovertakelsen har sultan Qaboos lagt vekt på nasjonal enhet, noe som ikke har gitt mye rom for pluralisme i det offentlige rommet, paradoksalt nok, ettersom Oman er et land med en svært sammensatt befolkning.

I motsetning til sine oljerike naboer De forente arabiske emirater, Bahrain og Qatar - men i likhet med sin mindre velstående nabo Jemen, har Oman alltid hatt en sterk nasjonal identitet. Denne identiteten skriver seg hovedsakelig fra ibadi-islam, en trosretning som utgår fra en tidlig utbrytergruppe innen islam og som ble etablert som offisiell religion i Oman allerede på 700-tallet. ${ }^{\mathrm{I}}$

Den swahili-omanske befolkningen, derimot, er hovedsakelig shafeei-sunni, en variant av sunni-islam som er den vanligste trosretningen i Øst-Afrika.

Det er nesten umulig å vite hvor mange av borgerne i dagens Oman som faktisk praktiserer ibadi-islam. Sultan Qaboos har lagt vekt på å integrere også andre muslimer i den offentlige religionsutøvelsen, for eksempel ved å understreke at alle muslimer er velkomne til å be i alle moskeer. Dette ble blant annet understreket ved åpningen av den storslagne Sultan Qaboos Stormoské i 2002.

Noen anslag finnes likevel. Dale Eickelmann anslo i I980 at cirka 30-35 prosent av Omans borgere var sunnimuslimer. ${ }^{2}$ Etter den tid har befolkningen økt til 3 millioner, hvorav cirka 600 oo० (cirka 20 prosent) er ex-patriates av ulike opprinnelser. Statistikker fra 2000-tallet oppgir andelen ibadier til å ligge på mellom 70-75 prosent av landets borgere, altså av cirka 2,4 millioner mennesker. ${ }^{3}$ Dette skulle gi et tall på cirka I,7 millioner ibadier. De øvrige 700 ooo til 800 ooo er antatt å være sunnimuslimer, men med en liten andel shiamuslimer. 
Hvem er så disse sunnimuslimene som man møysommelig kan grave frem fra statistiske årbøker? Mange av dem er baluchier fra det sørvestlige området i dagens Pakistan, andre kommer fra grenseområdene mot Emiratene og Saudi-Arabia. I tillegg kommer mesteparten av befolkningen fra den sørligste provinsen som er kulturelt knyttet til Jemen. Til slutt har vi også omanske borgere med bakgrunn fra ØstAfrika. Hvor mange de er, sier imidlertid tallene ikke noe om.

\section{Swahili-omaneren i historien}

I europeiske beskrivelser av Oman fra I800- og tidlig I900-tall er det praktisk talt ikke en eneste swahili-omaner å finne. Det som dukker opp av personer med afrikansk opprinnelse, er uten unntak slaver og dermed ikke i nærheten av å være det som i dagens nasjonalstater kalles "borger". ${ }^{4}$

At swahili-omaneren ikke er å finne i historiske beskrivelser av Oman har sin naturlige forklaring. Han (og hans familie) befant seg nemlig i Øst-Afrika, der den omanske sultanen Sayyid Said bin Sultan hadde etablert omansk styre over kystområdene i dagens Kenya og Tanzania. I I832 etablerte sultanen like godt hovedstaden for sitt nye, transoceanske imperium på øygruppen Zanzibar. Dette skulle forandre Zanzibar By til det ugjenkjennelige.

Der det før hadde stått et portugisisk fort, et par steinhus og en klynge med stråhytter, vokste det frem en metropol i østafrikansk målestokk, et handelsentrepôt uten sidestykke. I I770 bodde rundt 300 omanere i byen. I I8I9 hadde tallet økt til Io00, mens i I 840 var cirka 5000 omanere permanent bosatt i Zanzibar By. ${ }^{5}$ Fra I870tallet antar man at minst I2 000 første- og andregenerasjonsomanere var bosatt på
Zanzibar alene. I tillegg kom alle som bodde $\mathrm{i}$ de øvrige byene langs den østafrikanske kysten. Disse var handelsfolk, plantasjeeiere (Zanzibar var på slutten av I80o-tallet verdens hovedleverandør av nellik), militære, skriftlærde og personell knyttet til sultanatet.

Den omanske befolkningen på Zanzibar var transnasjonal - det vil si at de beholdt tilknytning til familien i Oman samtidig som de knyttet forbindelser til samfunnet $i$ Øst-Afrika. En slik forbindelse var ekteskap og konkubinat mellom omanske menn og kvinner fra den swahilitalende befolkningen. Ettersom omansk stammetilhørighet ble regnet partilineært, kunne sønner og døtre av slike forhold opprettholde sin status (og arverett) også vis-à-vis familien i Oman. Det de derimot ikke beholdt, var det arabiske språket.

Forskning tyder på at barn av omanskzanzibarske ekteskap vokste opp med å snakke morsmålet, det vil si swahili. Dette er paradoksalt, ettersom alt arabisk hadde svært høy status på Zanzibar. Ytre kjennetegn på "arabiskhet", som hvit kanzu/dishdasha (fotsid kjortel) og krumsabel, ble holdt sterkt i hevd blant omanske familier, mens nye generasjoner altså ikke lærte det arabiske språket hjemme. I stedet ble unge gutter sendt til Koranskoler for å lære farsmålet. I ı9ı8 ble det til og med utformet en egen, arabisk grammatikk for å lære "arabiske” gutter på Zanzibar å skrive og snakke arabisk, ${ }^{6}$ og forfatteren selv bemerket i forordet at "bare få” av disse var i stand til å formulere seg på språket.

Et annet kulturtrekk som gradvis forsvant var ibadi-islam. Til tross for at sultanatet opprettholdt ibadisme som offisiell religion, var det stadig flere fremstående 
omanske familier som praktiserte sunniislam, som den øvrige zanzibarske befolkningen. I noen tilfelle vakte dette reaksjoner fra sultanatets side, men stort sett foregikk prosessen uten dramatikk.

Mellom cirka I860 og I960 var den typiske swahili-omaneren altså bosatt i ØstAfrika, og aller helst i Zanzibar By, der sultanatet besto som britisk protektorat frem til uavhengigheten i ig63. Han (og i noen tilfeller hun) besøkte gjerne Oman fra tid til annen, men i all hovedsak var dette en befolkning som regnet sin tilhørighet først og fremst til Zanzibar, til et kosmopolitisk og multietnisk samfunn der de selv sto høyt på rangstigen.

Ved uavhengigheten i desember I963 ble Zanzibar et konstitusjonelt monarki under sultan Jamshid b. Abdullah Al Bu

\section{Da de omansk-zanzibarske familiene vendte "hjem", var det etter flere generasjoners utlendighet.}

Saidi. I den nye regjeringen satt flere swahili-omanere, deriblant landets nye utenriksminister Ali Muhsin Al Barwani (I9I9-2006).7 Den nye politiske ordenen skulle imidlertid bli et kortvarig eksperiment.

\section{Revolusjon på Zanzibar}

Revolusjonen på Zanzibar fant sted i løpet av noen dager i januar i964. Nå ble arabisk identitet, tidligere en kilde til status og konkrete privilegier, plutselig en ulempe. Et sted mellom 5000 og Io 000 mennesker ble drept. Anslagene er svært usikre, ettersom revolusjonen fortsatt er et ikke-tema på Zanzibar, både fra offisielt hold og i privat sammenheng. Selv de som ble direkte ofre for hendelsene, er vanskelig å få i tale. Den ekstreme voldsbruken og den gjennomgripende splittelsen av et helt samfunn har gjort at flertallet, uansett side, har valgt taushet for å legge det hele bak seg.

Etter revolusjonen fulgte en massiv flyktningstrøm fra Zanzibar. Praktisk talt alle som hadde tilknytning til $\mathrm{Bu}$ Saidi-sultanatet (og som hadde finansiell mulighet til det), forlot øya. Dhower, seilbåter som gjennom århundrer hadde fraktet varer og mennesker (inkludert slaver) til og fra Zanzibar, ble nå tatt i bruk for å smugle folk ut. Fra naboøya Pemba dro skipene om natten på korte turer over til Mombasa. Sultanen selv og hans familie reiste fra Zanzibar. Umar b. Sumayt, den fremste islamske dommeren på Zanzibar, forlot øya sammen med sitt barnebarn og en rekke av sine trosbrødre. Ali Muhsin Al Barwani ble fengslet og satt ti år i ulike tanzanianske fengsler. ${ }^{8}$

Spørsmålet var hvor flyktningene skulle reise. Oman var på i96o-tallet et lukket, fattig og tørt land uten utdanningsinstitusjoner og med totalt fem kilometer asfaltert vei. Hva kunne Oman tilby en utdannet, kosmopolitisk befolkning, som gjennom mer enn et århundre hadde levd i et åpent, om enn kolonisert samfunn? Alternativet var Europa og i første rekke kolonimakten England. Sultan Jamshid valgte det siste, men mange foretrakk, tross alt, å reise til sine oldefedres hjemland.

\section{De "hjemvendte" i Oman}

Da de omansk-zanzibarske familiene vendte "hjem", var det etter flere generasjoners utlendighet. Man kan spørre seg 
om det overhodet var snakk om en hjemvending til tross for at flyktningene bar omanske etternavn og alle ytre kjennetegn på å være av arabisk avstamming.

Realiteten var at Oman var et fremmed land for mange av de "hjemvendte". Til tross for at de på Zanzibar var definert som arabere, snakket bare et fåtall arabisk. Flyktningene som nå kom til Muscat var også vant til en helt annen livsstil enn den Muscat kunne tilby. Der Zanzibar hadde vært kosmopolitisk, multireligiøs og utadvendt, var Muscat under sultan Taimur lukket, innadvendt og tildels intolerant overfor folk utenfra.

Zanzibarerne hadde ofte utdanning fra britiske eller statlige skoler, i motsetning til jevnaldrende i Oman som ikke hadde andre utdanningsmuligheter enn de tradisjonelle madrasaene. Resultatet var at zanzibarerne kom til å utgjøre en egen gruppe, en ny type omaner med en helt annen erfaring enn sine landsmenn som var født i Oman. Slik situasjonen var i landet, fantes det svært få arenaer der de kunne bruke sine kvalifikasjoner, og mange forlot etter hvert Oman.. De som ble igjen, utgjorde en tildels isolert gruppe.

Dette forandret seg imidlertid på I970tallet. Etter sultan Qaboos' maktovertakelse i I970 og etter at oljeproduksjonen kom i gang, ble det i Oman lagt stadig sterkere vekt på nasjonal enhet. Skoler og universiteter ble bygget, og samfunnet ble åpnet for impulser utenfra. Den generelle tidsånden var fylt av omansk nahda - gjenoppvåkning. Den nye økonomien ga plutselig muligheter for omanerne fra Zanzibar som nå ble ansett som en sårt tiltrengt ressurs for landet. Samtidig ble Zanzibar, under et strengt nasjonalistisk og sosialistisk regime, stadig mer isolasjonistisk. Etter revolusjonen i i964 fikk bare kinesiske og østeuropeiske fagfolk innreise, mens arabiske skip av alle slag ble nektet anløp til Zanzibar Havn.

Rundt I980 var situasjonen snudd på hodet: Oman var betydelig rikere enn Zanzibar, og mer åpent. Stagnasjonen og en voksende økonomisk krise tvang frem en liberalisering på Zanzibar. Makthaverne hadde behov for nyinvesteringer, og søkte disse $i$ arabiske land - først og fremst i Oman - og gamle, familiebasert økonomiske forbindelser kunne reaktiveres.

I kjølvannet av dette ble familier gienforent (igjen, og denne gangen på Zanzibar) etter å ha vært adskilt siden I964. Fra I990-tallet var "transoceanske" familier igjen et vanlig fenomen på Zanzibar: storfamilier der deler av slekten bodde i Oman, deler på Zanzibar. Onkler og tanter bosatt i Oman tilbrakte de varme sommermånedene på Zanzibar; sønner og døtre bosatt på Zanzibar ble sendt til Oman for skolegang. Gradvis begynte familier å kjøpe tilbake hus i Zanzibar By som hadde blitt nasjonalisert under revolusjonen. Det har blitt opprettet direkte flyavganger mellom Muscat og Zanzibar, først med Gulf Air i I993 og senere med Air Oman som i 2002 lanserte Muscat-Zanzibar som "innenlandsrute".

Denne translokale identiteten har spredd seg også utover de tradisjonelle forbindelsene mellom Muscat og Zanzibar. I takt med at rikdommen og åpenheten har økt i Oman, har stadig flere omanere, og kanskje særlig swahili-omanerne, tatt utdannelse og/eller bosatt seg i Europa eller USA. Der har de møtt landsmenn fra Zanzibar, blant annet mange som forlot øya som følge av de politiske problemene på slutten av I990-tallet. Slik oppstår nye 
zanzibarske og zanibar-omanske samfunn. Det som ikke har skjedd, er at folk flytter. Swahili-omanerne har hatt en tendens til å bli boende i Muscat som regel på grunn av mistillit til makthaverne i Zanzibar (Zanzibars revolusjonsråd er et navn som ikke klinger godt hos flyktningene fra I964). Personer med omansk bakgrunn i Zanzibar har også hatt en tendens til å bli boende, hovedsakelig fordi det har vært vanskelig å få statsborgerskap i Oman, noe som krever beviselig omansk bakgrunn i farslinjen.

\section{Fra Muscats forsteder til Zanzibar By}

Forstaden al-Khoud ligger like ved Muscats flyplass og er et av mange nye nabolag i byen. Hvite, romslige eneboliger ligger på rekke og rad i ørkensanden, skinnende symboler på det nye Oman. Her har gatene ikke navn, men nummer, og husene er like. Det er ikke lett å finne frem, men etter regelmessige besøk i I999 og 2002, lærte jeg meg omsider veien til tidligere utenriksminister, nå forfatter og poet Ali Muhsin Al Barwanis hus. Den da 82 år gamle og nesten blinde Al Barwani hadde kommet til Oman via Dubai der han først bosatte seg etter å ha blitt løslatt av Tanzanias første president, Nyerere, i I974.

I dette husholdet snakket alle swahili. Hans døtre og sønner, barnebarn, fettere og kusiner, nieser og nevøer, samt en stadig strøm av besøkende fra Zanzibar, venner, slektninger, tidligere naboer, politiske kampfeller og motstandere. Alle kom jevnlig til huset for å diskutere politikk, litteratur og religion med "shaykh Barwani". All diskusjon foregikk på swahili, og i adskillig friere former enn det som var vanlig blant omanere med omansk bakgrunn. Alle i familien er velutdannete, både kvinner og menn. For den eldre generasjonen var alternativet til swahili engelsk (med unntak av Al Barwani selv som var flytende i arabisk etter en klassisk, islamsk utdannelse i Zanzibar og Egypt). De yngre, derimot, var komfortable med arabisk etter skolegang ved omanske utdanningsinstitusjoner. Imidlertid brukte også de hovedsakelig swahili seg imellom. Den eldste generasjonen var preget av nostalgi for et tapt hjemland og en tapt politisk drøm. De yngste så fremtiden lysere i møte, en fremtid der to hjemland var en selvfølge og en kilde til muligheter snarere enn problemer.

I februar 2006 befant jeg meg på Zanzibar. En morgen fikk jeg beskjed om å komme til madrasaen på hjørnet, straks. I døren møtte jeg Bibi Fatuma, en kvinne på rundt 60 år som jeg har kjent i mange år. Hennes livshistorie er et typisk eksempel på transnasjonalt levesett og identitet i dagens Zanzibar og Oman. Både hun og hennes første mann var av delvis omansk bakgrunn. Under revolusjonen ble mannen hennes drept, og siden hun selv ikke var omansk på farssiden, hadde hun liten mulighet til å bosette seg i Oman. Hun giftet seg i stedet på nytt og fikk flere barn som nå er voksne. Søsteren kom seg til Oman etter revolusjonen, og Fatuma har besøkt henne der flere ganger. Sønnene hennes har alle hatt lengre opphold i Oman og snakker et gangbart skolearabisk. Døtrene har utdanning fra Zanzibar og Dar-es-Salaam, og to av dem er gift med zanzibarere med tilsvarende omansk bakgrunn.

Nå hadde Fatuma nyheter fra Oman. Hun fortalte med bekymring i stemmen at Ali Muhsin Al Barwani var svært syk. Tekstmeldinger, e-poster og tilreisende hadde brakt nyheten om Barwanis sykdom til 
hjørnet av Zanzibar By der jeg bodde, og nå sto Bibi Fatuma i døren og var sørgmodig på vegne av en gammel zanzibarsk landsmann, som lå for døden. Da Al Barwani døde den 20. mars 2006, var jeg tilbake i Norge, men også her nådde nyheten meg raskt gjennom e-poster fra Zanzibar, Oman, Canada, USA og Sør-Afrika. Transnasjonale liv blir til transnasjonal død og til minneord som spres på internett, via SMS, av reisende mellom de to gamle hovedstedene Muscat og Zanzibar.

Kanskje er det her, i rommet mellom dem og i spennet mellom lokale og globale politiske, økonomiske og kulturelle prosesser, at vi finner swahili-omanerne, forkledd som zanzibarere, Golf-arabere, amerikanere, kanadiere eller omanere. Kanskje er det nettopp som bindestrek vi finner dem - bindestreker som kan knytte sammen fortid og nåtid, her og et annet sted, og som representerer en levd enhet der nasjonale grenser og immigrasjonsregler representerer stengsler.

\section{$\cdot f \cdot$}

I Valerie J. Hoffmann, "The Articulation of Ibadı Identity in Modern Oman and Zanzibar", The Muslim World, Vol 94 (April 2004), 20I-2I6.

2 Dale F. Eickelmann, "From Theocracy to Monarchy: Authority and Legitimacy in Inner Oman, I935-I957", Int. J. Middle East Studies, I7, (1985), 3-24.

3 CIA Fact Files.

4 Europeiske beskrivelser fra kolonitiden bruker som regel betegnelsen "negro" - et begrep som i Arabia var synonymt med slave. Om dette var korrekt i alle tilfelle, er umulig å avgøøre. Se for eksempel: Mr. and Mrs. Bent, Southern Arabia, London, I900. Blant de mange folkegruppene i Muscats souk finner ekteparet Bent også "negroes from Zanzibar."

5 Bissel, B., City of Stone, Space of Contestation, PhD avhandling, University of Chicago, I999, I74.

6 Burhan Mkelle and Saleh bin Ali, Al-Tamrın. Book of Primary Lessons on Grammar, Part I Containing parts of Speech, Zanzibar Government Print, I9I8.

7 Ali Muhsin Al Barwani, Kujenga na kubomolewa Zanz- ibar (Kumbukumbuku), Dubai/Muscat, 2003.

8 Intervjuer med Ali Muhsin Al Barwani, Muscat, 1999 og 2002, samt intervju med Al Barwani, Al-Jazeera Info Centre, Gulf News, I6.0I.2004, www.aljazeerah.info

9 Eric Gilbert, "Oman and Zanzibar. The Historical Roots of a Global Community", i: H.P. Ray \& E.A. Alpers (eds.), Cross Currents and Community Networks. The History of the Indian Ocean World, Oxford University Press, 2006. 